RECONHECER-SE NO OUTRO:

\title{
A FORMAÇÃO IDENTITÁRIA E OS JOVENS DO FUNK
}

\author{
Inês Quiroga Coelho'
}

RESUMO: A partir do material fotográfico produzido em uma pesquisa sobre bailes funk da cidade de Belo Horizonte, este artigo busca adentrar e refletir sobre a conexão entre a construção identitária e o reconhecimento, à luz da noção de habitus de Pierre Bourdieu e das reflexões de Axel Honneth acerca das relações de reconhecimento intersubjetivas. Desse modo, as fotografias tornaram-se não somente um ponto de partida para a descrição detalhada da estética específica incorporada pelos jovens frequentadores dos bailes, mas também molas inspiradoras que me lançaram ao encontro da relação entre a formação identitária e o ato de reconhecer-se no outro presentes no ambiente do funk.

PALAVRAS-CHAVE: Formação identitária, reconhecimento, baile funk

Recebido em: outubro de 2012 Aceito em: maio de 2013

Para citar este artigo:

COELHO, Inês; Reconhecer-se no outro: a formação identitária e os jovens do funk. In: Revista Intratextos, 2013, vol 4, no1, p. 107-118. DOI: 10.12957/intratextos.2013.8519

1 Inês Quiroga Coelho é mestranda do Programa de Pós-graduação em Ciências Sociais da Universidade do Estado do Rio de Janeiro e pesquisadora do INARRA - Imagens, Narrativas e Práticas Culturais/UERJ. Bolsista Capes. Email: inesitaquiroga@hotmail.com 


\section{O início}

Abrir a gaveta com antigos materiais de pesquisa e tirar o pó de questões que, naquela época, pareciam merecer um olhar mais atento e refinado é, sem dúvida alguma, instigante. É, poderíamos dizer, uma volta ao tempo, uma viagem à memória em um outro corpo, com uma outra bagagem de referências e experiências. A escrita deste trabalho reflete, portanto, a tentativa de esboço de um novo olhar sobre parte de um material coletado durante o ano de 2008 e cuja sistematização e análise, em sua integralidade, deu origem à minha monografia de final de curso, defendida em abril de 2009.

A pesquisa buscou, a partir de um trabalho de campo realizado em bailes funk da cidade de Belo Horizonte, entender um pouco do mundo da periferia, através de seus aspectos visuais, e verificar as possibilidades de conexão entre antropologia e imagem. Essa teve como base referenciais teóricos vinculados tanto ao estudo da antropologia visual, quanto ao estudo do corpo, além de fotografias e descrições de minhas observações em campo.

O presente trabalho, no entanto, não aborda discussões dos campos da antropologia visual e do corpo, mas sob um novo viés teórico, teve como ponto de partida o material fotográfico $^{2}$ dessa pesquisa. Portanto, busco adentrar e refletir sobre a conexão entre a construção identitária e o reconhecimento, através das relações de reconhecer-se no outro reveladas pelas imagens.

\section{Contextualizando a pesquisa e os jovens do funk}

Desde 2007, vinha acompanhando os trabalhos de uma organização não-governamental ${ }^{3}$ cujo público principal são jovens moradores do Aglomerado da Serra, a maior favela da cidade

2 O material fotográfico dessa pesquisa é composto por fotografias tiradas por mim e por Henrique Marques, amigo e colega de trabalho na ONG Contato - Centro de Referência da Juventude. Desse modo, vale a pena mencionar que, ciente de todas as questões relacionadas às inúmeras possibilidades do olhar daquele que está por detrás da câmera, acredito não ser substancial as diferenças entre as minhas fotos e as dele, uma vez que, antes de ir a campo, mantínhamos um diálogo constante sobre o meu objeto de estudo, proporcionando, assim, uma aproximação entre os nossos olhares.

3 ONG Contato - Centro de Referência da Juventude

INTRATEXTOS, Rio de Janeiro, Número Especial 4(1): 107-118, 2013. ISSN 2176-6789 
de Belo Horizonte ${ }^{4}$. Esses jovens, participantes dos projetos sociais implementados pela ONG, despertaram imensamente meu interesse pelo mundo da periferia. Assim, a realização dessa pesquisa teve como alicerce o desejo de adentrar esse universo, buscando entender possíveis relações entre os jovens moradores e seu contexto social.

Estimulada por uma disciplina de Antropologia do Corpo, realizada no âmbito do curso de graduação em Ciências Sociais da UFMG, comecei a frequentar os bailes funk, promovidos pela casa de shows Cocobongo, localizada na região central de Belo Horizonte. O trabalho de campo foi realizado em dois períodos distintos: de abril a junho e outubro a dezembro de 2008. Estes dois períodos de observação foram marcados por uma diferença significativa: o foco do olhar. $\mathrm{Na}$ aproximação inicial, procurava compreender o baile funk como um todo - espaço físico, frequentadores, indumentária, música, dança - e a aproximação e movimento dos corpos nas danças. No segundo momento de observação, meu olhar voltou-se especificamente para a estética dos frequentadores - cabelo, indumentária, gestos e posturas corporais. Neste contexto, vale a pena esclarecer que entendo estética, conforme propõe David MacDougall (2006, p.98), como “(...) pouco a ver com noções de beleza e arte, mas sim com uma gama muito mais vasta de experiências sensoriais culturalmente padronizadas.”.

Os bailes funk da casa de shows Cocobongo ocorriam toda sexta-feira a partir das 22 horas e sua programação era bastante diversa. Os frequentadores eram, em sua grande maioria, jovens, homens e mulheres, entre 18 e 30 anos, de cor negra e parda. Apesar de se deslocarem de diferentes áreas da cidade para ir ao baile, seus locais de moradia eram, predominantemente, regiões localizadas na periferia da cidade ou vilas e favelas erguidas em meio a bairros considerados de classes média e alta.

Desse modo, esses jovens compartilhavam não somente o ambiente do baile funk, mas também contextos sociais similares, marcados pela falta de infraestrutura e serviços básicos e pela violência e fragmentação territorial, impostas pelo domínio de diferentes grupos armados que buscam suprir as carências existentes nestes espaços urbanos. A ausência e a exclusão, que

$4 \quad$ O Aglomerado da Serra conta com aproximadamente 46 mil habitantes, sendo formado por seis comunidades vizinhas: Marçola, Nossa Senhora de Fátima, Nossa Senhora Aparecida, Nossa Senhora da Conceição, Novo São Lucas e Santana do Cafezal. Cf.: site da prefeitura de Belo Horizonte: www.pbh.gov.br

INTRATEXTOS, Rio de Janeiro, Número Especial 4(1): 107-118, 2013. ISSN 2176-6789 
permeiam a vida desses jovens em diferentes âmbitos, podem ser vistas, então, como condições comuns, compartilhadas.

Assim, era facilmente reconhecível aquele que não pertencia ao grupo, uma vez que o compartilhamento de interesses e condições sociais comuns e a incorporação de uma estética específica - intervenções nos cabelos, bonés, camisas esportivas, colares, brincos, maneiras de falar e gesticular - indicavam, claramente, onde aqueles sujeitos estavam 'inseridos'.

\section{Destrinchando o material etnográfico}

Ao mergulhar nas fotografias do baile funk a característica estética que inegavelmente

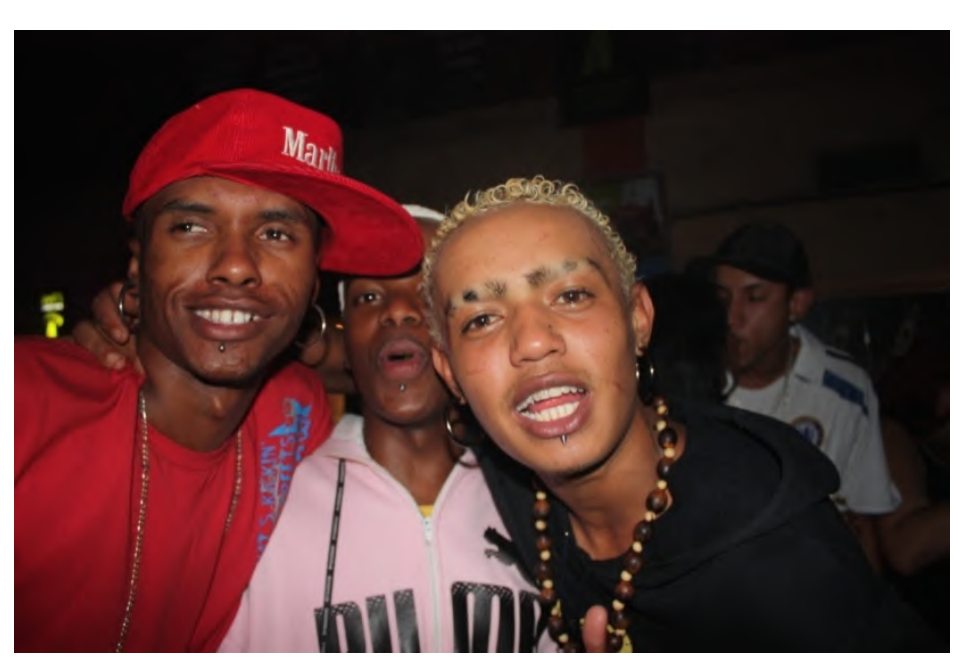
salta aos olhos daquele que nunca frequentou aquele ambiente são os cabelos dos frequentadores. Com um único olhar, torna-se nítido que uma característica é peculiar a todos os frequentadores do baile de sexo masculino: a intervenção nos cabelos.

Aqueles que não fazem nenhum tipo de intervenção, por menor Foto 1 que seja, utilizam o boné e não o tiram da cabeça em nenhum momento. Os tipos de modificação dos cabelos variam razoavelmente, no entanto, três modelos principais destacam-se: os descoloridos, os "arrepiados" com gel e os desenhados com lâmina de barbear. $\mathrm{Na}$ grande maioria das vezes, em um único frequentador podemos ver dois, três e até quatro tipos de intervenção distintos.

Os desenhos aparecem também nas sobrancelhas dos frequentadores. Partes das sobrancelhas são raspadas dando a impressão de linhas diagonais. Essa marca corporal pode ser vista em parcela significativa dos homens que vão aos bailes, no entanto, somente a partir de uma análise mais atenta das fotografias pude perceber quão frequente era essa intervenção e, 
principalmente, a uniformidade das elaborações. Todos aqueles que levavam essa marca nas sobrancelhas apresentavam duas a três linhas diagonais que variavam em termos de espessura.

A indumentária dos jovens é predominantemente esportiva. Bermuda de tactel, calça jeans, camiseta $t$-shirt, tênis e boné são as principais vestimentas que compõem a estética do grupo. As bermudas de tactel são iguais às usadas por surfistas e variam de cores lisas a estampas florais, abstratas e/ou geométricas. As calças jeans apresentam diferenças quanto à tonalidade do tradicional índigo blue até tons azul acinzentados e quanto aos recursos decorativos - número de bolsos, retalhos, ilhoses, costuras pespontadas, etc. No entanto, uma característica é constante: todas as calças apresentam uma modelagem oversized.

As camisetas t-shirt são, em sua grande maioria, de times de futebol e/ou de marcas esportivas. Entre as $t$-shirts de times de futebol há um maior domínio das de times internacionais, como, por exemplo, o espanhol Real Madrid Club de Fútbol e o argentino Club Atlético Boca Juniors; no entanto, não raro vê-se também camisetas dos times mineiros

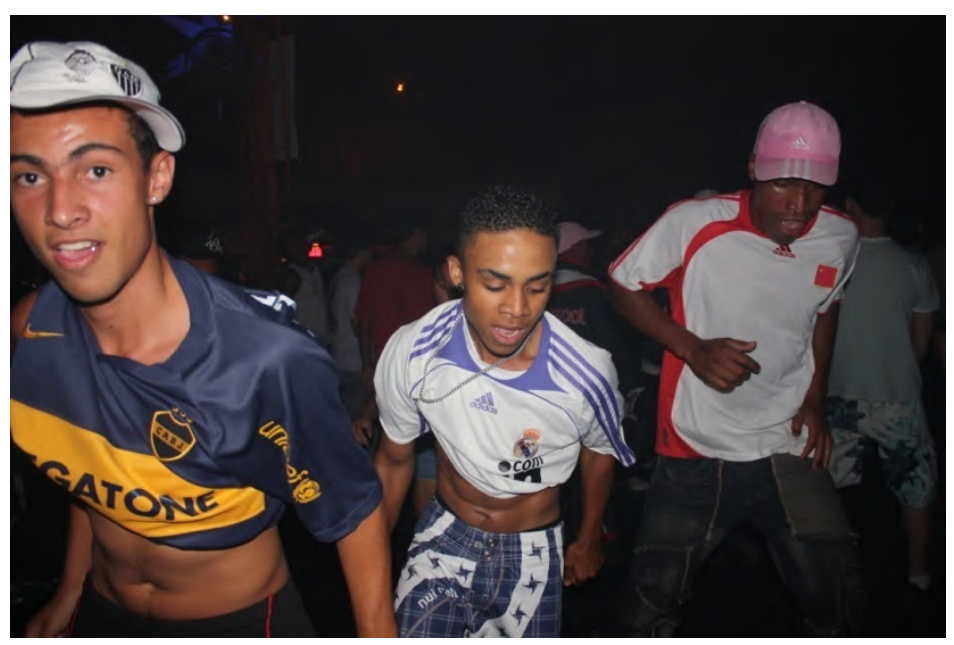

Foto 2

- Cruzeiro Esporte Clube e Clube Atlético Mineiro.

As camisetas $t$-shirt de marcas esportivas variam desde camisetas que levam estampadas o logotipo das marcas Adidas, Puma, Nike, Billabong, Reef e Ecko Unltd até camisetas com escritos em inglês e estampas relacionadas ao surfe, porém de marcas pouco conhecidas. É importante destacar que muitas das camisetas de marcas desconhecidas tentam imitar os desenhos e logotipos de marcas famosas, como, por exemplo, ao exibir nas mangas duas listras ao invés das três listras oficiais da Adidas. 


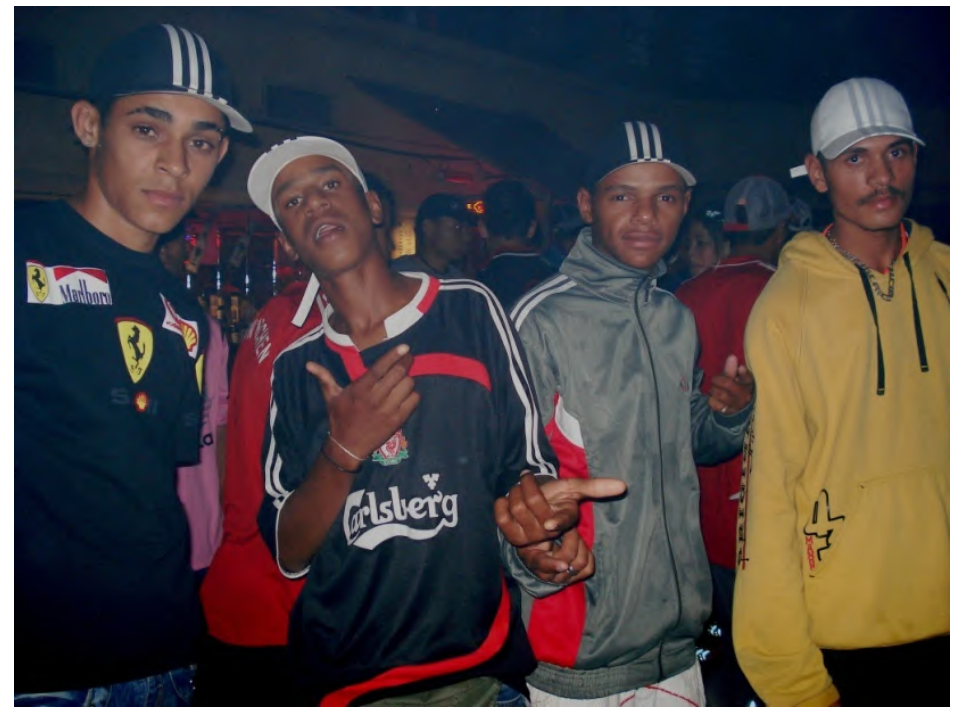

Foto 3

Como mencionado antes, os bonés estão sempre presentes na cabeça daqueles que não intervêm em seus cabelos. Esse acessório é utilizado, na grande maioria das vezes, com a aba para frente, sendo a marca mais comum, assim como nos demais itens indumentários, a alemã Adidas.

As roupas utilizadas pelos frequentadores dos bailes funk, à primeira vista, em muito se assemelha à estética dos chamados playboys, no entanto alguns acessórios, por eles incorporados, conferem uma autenticidade própria à sua estética. Brincos, colares e piercings acrescentam à vestimenta esportiva a marca do grupo, tornando-os bastante distintos dos filhos da classe média.

Estes acessórios fazem parte da indumentária de parte significativa dos frequentadores dos bailes, estando, muitas vezes, todos presentes em um único indivíduo. Os brincos são usados não somente em uma orelha, mas nas duas, sendo predominantes os feitos de prata com uma pedra de strass na ponta. Uma menor parte utiliza brincos em formato de argola feitos de prata, madeira e/ou coco - estilo indígena.

Os colares mais comuns têm formato de corrente e são feitos de prata. O tamanho, em termos do comprimento e da espessura dos elos, varia bastante. Alguns apresentam pingentes com desenhos diversos elaborados somente em prata ou com

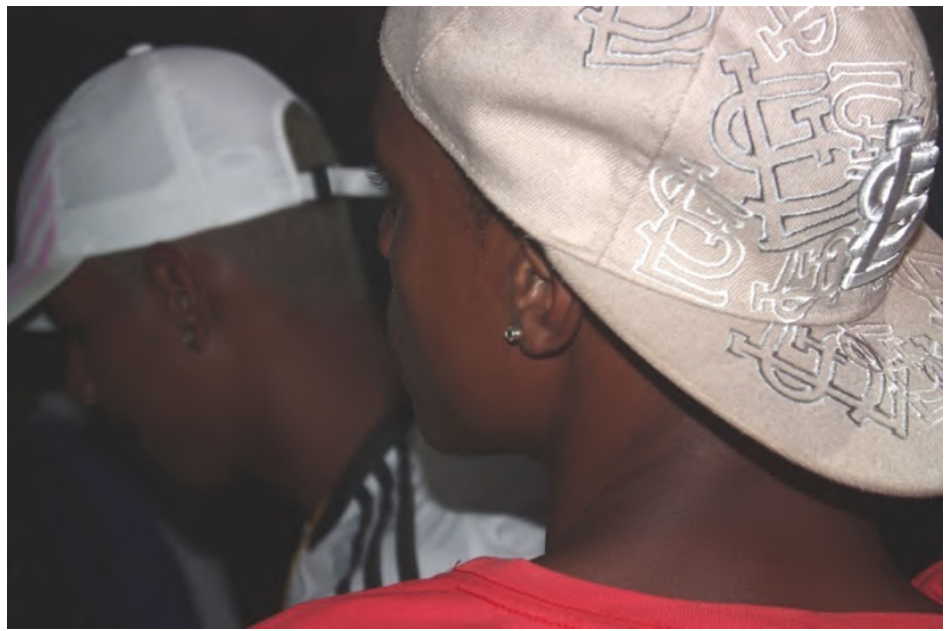

Foto 4 
pedras de strass. Colares, conhecidos como étnicos, produzidos com madeira, coco e/ou sementes, também são encontrados.

Durante minhas idas a campo pude perceber que os gestos e posturas corporais dos frequentadores dos bailes funk eram também característicos, no entanto, somente quando comecei a

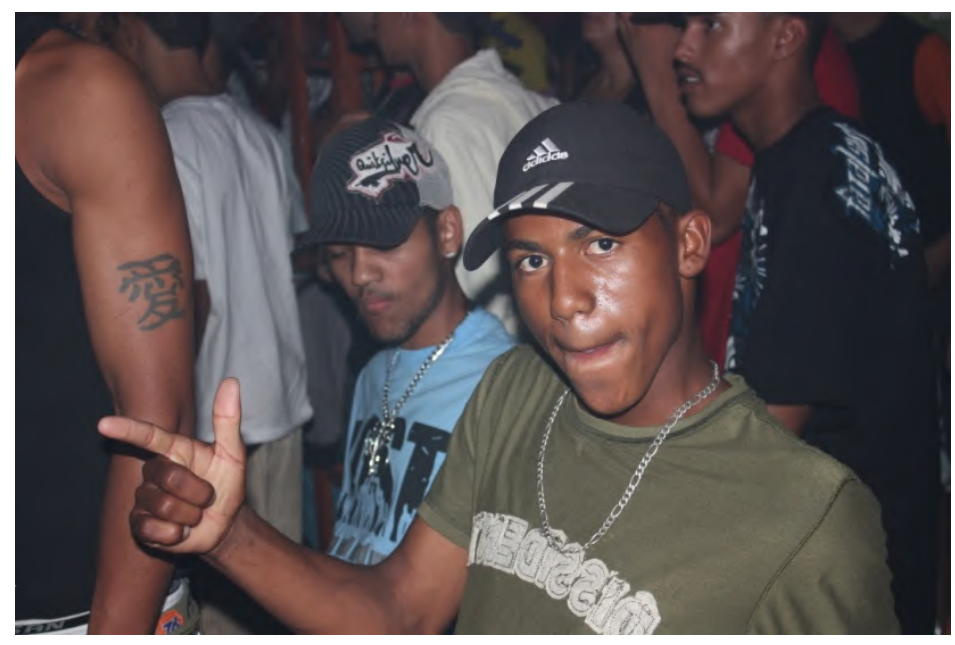

Foto 5 analisar as fotografias tiradas é que me dei conta do quão marcante era a maneira como eles se posicionavam frente a mim e à câmera fotográfica.

O fato de serem, muitas vezes, chamados para posar perante esta, permitiu aos frequentadores ter controle sobre o que seria fotografado, assumindo, dessa maneira, expressões corporais e faciais específicas. Gestos e posturas que ao se afastarem do visor da câmera e do meu olhar

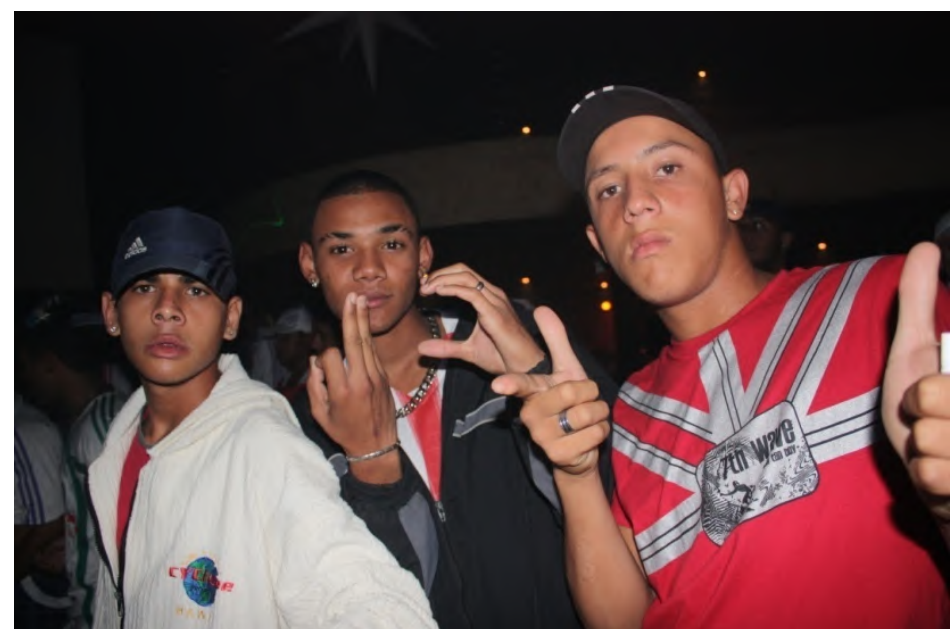

Foto 6 eram desfeitos e readotados somente em circunstâncias específicas de sua interação dentro do contexto do baile.

Diante de mim e da máquina fotográfica, muitos dos frequentadores incorporavam uma "cara de mau". Levantavam levemente o peito, erguiam um pouco a cabeça e esboçavam uma expressão de desagrado e/ou ironia. Eles revelam, desta forma, através de suas posturas corporais, ares, ao mesmo tempo, de superioridade, agressividade e sarcasmo. Exibiam, também, um olhar fixo e marcante que evocava força ativa e vigor. Alguns deles não adquiriam essa postura ao serem fotografados, porém exibir um sorriso aberto no rosto era raro. 
Grande parte dos jovens do baile, ao posarem para a câmera, fazia gestos com as mãos. O dedo polegar levantado, o anular (e algumas vezes o médio também) esticado e o braço dando a impressão de que se aponta em alguma direção era o gestual que mais se destacava, seja por sua repetição, seja pelo que remete. O significado deste símbolo corporal é inconfundível. Em uma ida a campo pude presenciar uma apresentação em que um MC (MC Caçula) cantava uma música falando sobre tiroteios em uma comunidade. Ao mesmo tempo em que o MC fazia este gesto, ouviam-se ao fundo sons de tiros. A ideia de que se trata de uma arma não pode ser mais explicita. Outros gestos de mão aparecem nas fotografias com menor frequência, porém quase sempre remetendo a algo provocador e, de certa forma, agressivo.

Mesmo sem pretender realizar uma análise aprofundada dos significados simbólicos contidos nos gestos e poses que se deixam ver através dessas fotografias, uma vez que vai além do âmbito reflexivo proposto por este trabalho, é impossível não relacionar essas características distintivas desses jovens aos seus contextos de vivência, permeados por situações de ausência, exclusão e imposição da violência, seja por parte do próprio Estado, seja de grupos armados.

\section{Reconhecendo-se no outro}

Como molas inspiradoras, as fotografias dos jovens do funk nos lançam ao encontro da noção de que a formação da identidade pessoal dos sujeitos está vinculada à experiência de reconhecimento, isto é, somente no momento em que um indivíduo se vê em outro indivíduo é que esse toma conhecimento de suas particularidades e de sua própria condição enquanto sujeito. É importante ressaltar que as relações de reconhecimento acontecem em distintos espaços culturais e sob variadas formas, porém este trabalho tem como foco somente as possíveis relações que podem ser vislumbradas no contexto do baile funk, através do material fotográfico coletado.

O indivíduo, ao longo de sua trajetória de socialização, não apenas participa de relações intersubjetivas em distintos âmbitos, mas constrói a sua identidade a partir dessas relações, uma vez que é nesse jogo relacional que ele passa a ver-se a si mesmo e aos outros.

O reconhecimento acontece na interação da vida diária dos sujeitos, nessa ocorre a formação do sujeito na medida em que o outro reconhece as faculdades e as qualidades de uma pessoa como valiosas. Tal exaltação permite por sua vez que o sujeito conheça 
aspectos insubstituíveis da sua identidade, ao ponto de chegar a contrapor-se ao outro quando se confrontam duas identidades singulares. ${ }^{5}$ (RESTREPO, 2010, p. 181)

Segundo o teórico Axel Honneth, essas relações de reconhecimento estão presentes nas esferas da família, da sociedade e do Estado, sendo expressas de modos diferentes em cada uma dessas instâncias. Nas palavras do autor, o processo de constituição identitária de um sujeito perpassa:

(...) desde a esfera emotiva que permite ao indivíduo uma confiança em si mesmo, indispensável para os seus projetos de auto-realização pessoal, até a esfera da estima social em que esses projetos podem ser objeto de um respeito solidário, passando pela esfera jurídico-moral em que a pessoa individual é reconhecida como autônoma e moralmente imputável, desenvolvendo assim uma relação de auto-respeito. (HONNETH, 2003, p. 18)

Em meio às relações de reconhecimento existentes nestes três âmbitos, que apesar de distintos interligam-se, fronteiras simbólicas de diferenciação com os outros vão sendo erguidas, de modo a enfatizar o caráter particular de seus códigos.

\begin{abstract}
A estrutura de uma tal relação de reconhecimento recíproco é para Hegel, em todos os casos, a mesma: na medida em que se sabe reconhecido por um outro sujeito em algumas de suas capacidades e propriedades e nisso está reconciliado com ele, um sujeito sempre virá a conhecer, ao mesmo tempo, as partes de sua identidade inconfundível e, desse modo, também estará contraposto ao outro novamente como um particular. (HONNETH, 2003, p. 47)
\end{abstract}

No entanto, reconhecer-se no outro não significa somente oposição e contraste. Esse reconhecimento pode levar também à identificação e, consequentemente, à afirmação de um nós. Essa passagem do eu para o nós se dá, a partir do momento em que ao projetar-se em outro sujeito, o indivíduo depara-se com um outro que apresenta uma história comum, uma condição de existência similar. Pierre Bourdieu ao trazer à luz a noção de habitus nos apresenta um olhar possível sobre o significado desse elo comum, que permite a constituição de um processo de identificação e, assim, o trânsito de uma identidade individual para uma identidade coletiva.

É sua posição presente e passada na estrutura social que os indivíduos, entendidos como pessoas físicas, transportam com eles, em todo tempo e lugar, sob a forma de habitus. Os indivíduos "vestem" os habitus como hábitos, assim como o hábito faz o monge, isto é, faz a pessoa social, com todas as disposições que são, ao mesmo tempo, marcas da posição social (...). (BOURDIEU, 1983, p. 75) 
Para o autor, o habitus é o "princípio unificador e gerador de todas as práticas" (1983, p. 83) e estas práticas agrupadas formam um estilo de vida. Assim, ao 'vestirem' o mesmo habitus, os indivíduos incorporam modos de ser, preferências e códigos comuns.

O gosto, propensão e aptidão à apropriação (materiais e/ou simbólica) de uma determinada categoria de objetos ou práticas classificadas ou classificadoras, é a fórmula generativa que está no princípio do estilo de vida. $\mathrm{O}$ estilo de vida é um conjunto unitário de preferências distintivas que exprimem, na lógica específica de cada um dos subespaços simbólicos, mobília, vestimentas, linguagem ou héxis corporal, a mesma intenção expressiva, princípio da unidade de estilo que se entrega diretamente à intuição e que a análise destrói ao recortá-lo em universos separados. (BOURDIEU, 1983, p. 8384)

Assim, os jovens do funk ao compartilharem um mesmo habitus, uma vez que suas trajetórias são marcadas pela memória de um passado e pela vivência de um presente, em que perpassam situações comuns, sejam negativas ou positivas, incorporam características distintivas, tornando visível a sua identidade coletiva. Eles deixam de ser indivíduos isolados e passam a “ser-como-grupo". (CLARKE, 1976, apud, ABRAMO, 1994, p. 88) Nas fotografias, portanto, as intervenções nos cabelos, bonés, camisas esportivas, colares, brincos, gestos e poses dos jovens expressam sua inserção singular na sociedade e seu modo próprio de reconhecer e de se fazer reconhecer.

Esses símbolos distintivos, no entanto, ao mesmo tempo em que chamam à atenção para o pertencimento social, para a integração de determinado indivíduo a certo habitus, demarcam também aqueles que vivenciam condições de existência diferentes. Neste sentido, apesar de que, para Axel Honneth, uma tensão interna está presente em todas as relações de reconhecimento intersubjetivo existentes no âmbito da sociedade, no encontro entre indivíduos ou grupos de habitus diferentes torna-se ainda mais clara essa dimensão de conflito e o estabelecimento de uma luta por reconhecimento. Essa luta é, então, travada, uma vez que, de acordo com Honneth,

(...) um indivíduo só está em condições de identificar-se integralmente consigo mesmo na medida em que ele encontra para suas peculiaridades e qualidades aprovação e apoio também de seus parceiros na interação: o termo "honra" caracteriza, portanto, uma relação afirmativa consigo próprio, estruturalmente ligada ao pressuposto do reconhecimento intersubjetivo da particularidade sempre individual. (HONNETH, 2003, p. 56)

Assim, para o autor, somente através do conflito pode haver um reconhecimento mútuo, isto é, “só através da violação recíproca de suas pretensões subjetivas os indivíduos podem 
adquirir um saber sobre se o outro também se reconhece neles como uma 'totalidade'(...)." (2003, p. 63) Nas fotografias dos jovens frequentadores do funk, esse embate se faz presente através da interação entre os jovens e a antropóloga-pesquisadora que se encontra no instante fotográfico atrás da câmera. Gestos e posturas reveladoras de suas vivências e experiências são assumidas no exato momento da luta fotográfica, em busca da reafirmação de sua condição enquanto um sujeito específico.

Vemos, assim, através das imagens dos jovens frequentadores do baile funk, que relações de reconhecimento podem ser vislumbradas em duas dimensões dentro do contexto do baile: primeiramente, no reconhecer-se no outro dos jovens entre si, levando a um processo de identificação e, consequentemente, de construção de uma identidade coletiva e, em um segundo momento no encontro entre esses jovens e a antropóloga-pesquisadora, pertencente a um habitus distinto, incitando a instauração de uma luta por reconhecimento. Nesta dinâmica de embate e reconciliação, presente nestas duas dimensões, é cristalizada não somente a identidade individual de cada um dos frequentadores do baile, mas também uma identidade coletiva, que no caso destes jovens, busca, mais do que nunca, incluir-se em uma ordem que parece, constantemente, excluílos.

\section{Referências Bibliográficas}

BOURDIEU, Pierre. "Esboço de uma teoria da prática". In: ORTIZ, R. (org.). Pierre Bourdieu: sociologia. São Paulo: Ática, 1983, p. 46-81.

. "Gostos de classe e estilos de vida". In: ORTIZ, R. (org.). Pierre Bourdieu: sociologia. São Paulo: Ática, 1983, p. 82-121.

CLARKE, John. "Style". In: HALL, S; JEFFERSON, T. Resistence through rituals; youth subcultures in post-war Britain. London: Hutchinson and Co, CCCS. University of Birmingham, 1976 apud ABRAMO, Helena W. Cenas juvenis: punks e darks no espetáculo urbano. São Paulo: Scritta, 1994.

HONNETH, Axel. Luta por reconhecimento: a gramática moral dos conflitos sociais. São Paulo: Editora 34, 2003. 
MACDOUGALL, David. The corporeal image: film, ethnography, and the senses. New Jersey: Princeton University Press, 2006.

RESTREPO, Adrián. "Los jóvenes y sus luchas por el reconocimiento". Nómadas [online]. Bogotá, n. 32, p. 179-193, 2010.

RODAS, Francisco Cortés. "Reconocimiento y justicia: entrevista con Axel Honneth". Estudio Políticos, Medellín, n. 27, p. 9-29, jul/dez 2005.

\title{
SELF-RECOGNITION IN THE OTHER: THE IDENTITY CONSTRUCTION AND THE YOUTH OF FUNK BALLS
}

\begin{abstract}
Through the photographic material produced in a research about funk balls in the city of Belo Horizonte, this article intends to enter and reflect about the connection between identity construction and recognition in the light of Pierre Bourdieu's notion of habitus and Axel Honneth's reflection about the intersubjective relationships of recognition. Thus, the photographs were taken not only as a start point to the detailed description of the specific aesthetic incorporated by the young people that attend the balls, but also as a catapult throwing myself into the encounter of the relation between identity formation and the act of self-recognition in the other present in the funk environment.
\end{abstract}

KEYWORDS: Identity construction, recognition, funk ball 